\title{
Exploring links between foundation phase teachers' content knowledge and their example spaces
}

\begin{abstract}
This paper explores two foundation phase teachers' example spaces (a space in the mind where examples exist) when teaching number-related topics in relation to snapshots of their content knowledge (CK). Data was collected during a pilot primary maths for teaching course that included assessments of teacher content knowledge (CK). An analysis of a content-knowledge focused pre-test developed for the larger study indicated a relatively high score for one teacher and a low score for the other. Using Rowland's (2008) framework, an analysis of classroom practice showed associations between a higher CK and the extent of a teacher's example space and more coherent connections between different representational forms. Although no hard claims or generalisations of the link between teachers' example spaces and their level of mathematics content knowledge can be made here, this study reinforces evidence of the need to increase teachers' CK from a pedagogic perspective in order to raise the level of mathematics teaching and learning in the South African landscape.
\end{abstract}

Keywords: mathematics, foundation phase, teachers, number, examples, representations, content knowledge

Samantha Morrison, Wits School of Education.Email: samantha.morrison@wits.ac.za

South African Journal of Childhood Education | 2013 3(2): 96-111 | ISSN: 2223-7674 |৫ UJ

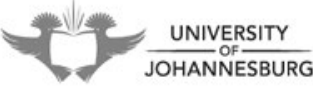




\section{Introduction}

South African learners' poor performance in mathematics is well documented in both national and international studies, for example the annual national assessments (ANA) (DBE, 2011a) and the Trends in International Mathematics and Science Study (TIMSS) (Mullis, Martin \& Fay, 2008). This poor learner performance in mathematics is mirrored in the performance of South African teachers in the comparative study conducted by Carnoy and Chisholm (2008) as well as in the statistics from the latest SACMEQ III study (Moloi \& Chetty, 2010). Broader evidence points to connections between mathematical content knowledge and mathematics teaching practices (NCTAF, 1996). Evidence also points to mathematical content knowledge being necessary, but not sufficient, for constructive classroom practice (Askew, Brown, Rhodes, Wiliam \& Johnson, 1997; Ball \& Bass, 2003). South African findings from studies of foundation phase numeracy teaching point to poor sequencing of examples (Venkat \& Naidoo, 2012) and limited ranges of examples in the low rates of task completion within and across lessons (Venkat, 2013) and more general slow pacing (Ensor et al., 2009; Reeves \& Muller, 2005).

Against this background, a content-knowledge focused in-service teacher training course was piloted as part of the Wits Maths Connect Primary (WMC-P) Project. The course aimed to improve participants' mathematical CK and teaching of mathematics in the classroom. In a broader master's study (Morrison, 2013), the author investigated the links between CK as measured on a course pre-test, number topic-focused course assessments and the teaching of number in classrooms of two foundation phase teachers with very different performance in terms of CK. In this paper, the author focuses specifically on contrasts in the selection and use of examples by these two teachers.

Following Bill et al.'s (2006) formulation, an example includes anything that is used as 'raw material' in the classroom setting for the purpose of generalisation, illustration of concepts, demonstration of possible variation and practising of a technique. Literature points to the importance of how examples are selected and used as this has bearing on what features the learners take note of, and consequently, on learners' mathematical understanding (Bills et al., 2006; Watson \& Mason, 2005). Within this use, how examples are represented in the classroom - in the form of objects, spoken words, pictures, written words and symbols such as numerals (Askew \& Brown, 2003) - are important for concept understanding in mathematics (Ball \& Bass, 2003; Heize, Star \& Verschaffel, 2009). Example spaces have been defined by Watson and Mason (2005) as a structured 'space' in one's mind where collections of interconnected examples exist. Rowland (2008) examines pre-service primary mathematics teachers' work with examples in relation to the categories of taking account of: variables, sequencing, representations and learning objectives.

Given evidence of widespread gaps in primary teachers' mathematical CK in South Africa and literature detailing the important role of examples, the author's interest was in understanding how these two issues were linked. The focus on early number in 
this study was motivated by literature which points to the importance of developing learners' number sense in the primary years (Anghileri, 2006; Askew et al., 1997; Haylock \& Cockburn, 2008; McIntosh, Reys \& Reys, 1992; Shumway, 2011), as well as problems identified in South African learner performance in this area (Schollar, 2008). The research question that guided this paper was:

- What insights about example spaces can be gained by observing teachers' selection and use of examples when teaching number-related tasks - taking variables, sequencing and representations of examples into account?

Understandings of early number and its teaching form the empirical field of this study; examples and analytical categories for understanding their selection and use form the conceptual framework. Both of these features are detailed in the following sections.

\section{Number sense}

Learners' flexibility in using number operations and procedures and their understanding of the relative effect of operating on numbers are considered as some of the essential components of number sense (Anghileri, 2006; Mclntosh et al., 1992; Shumway, 2011). According to Shumway (2011) number sense facilitates learners': recognition of patterns and relationships between numbers, efficient computation, reasoning ability, and problem solving abilities. Children who lack number sense face enormous barriers to learning mathematics because they see mathematics as a set of isolated, disconnected facts and algorithms which must be memorised and practised (Reys et al., 1999; Shumway, 2011). The four basic operations that constituted the syllabus for arithmetic in the past are still important for mathematics learning, but the emphasis within research findings suggest that they should not simply be taught as paper-and-pencil skills. Within addition and subtraction there is commentary that restricting conceptions of addition and subtraction to 'join' or 'take away' conceptions reduces the range of problems that learners are able to tackle (Carpenter, Fennema, Franke, Levi \& Empson, 1999). The body of work done by Carpenter et al. (1999) shows that there are different types of addition and subtraction problems that children must be exposed to, viz. join, separate, part-part-whole, and compare problems. These problem types are distinct in that children are initially likely to perform different actions to try to solve them (Carpenter et al., 1999). Similarly, these authors believe that learners use different initial direct modelling strategies to solve multiplication and division problems which they have grouped into multiplication, measurement division and partitive division problems based on the different information set types given in the problem and how learners solve these. These different problem types also represent different levels of complexity in early number learning, and Carpenter et al. have argued the need for learners to get exposure to the range of problem types to help them recognise the type of problems presented, and to solve them successfully (Carpenter et al., 1999).

The recently introduced Curriculum and Assessment Policy Statement (CAPS) has increased the weighting for Numbers, Operations and Relationships (Topic 1) from $50 \%$ 
to $65 \%, 60 \%$ and $58 \%$ for Grades 1,2 and 3 respectively (DBE, 2011b). This increase in notional time undergirds the author's exploration of teachers' selection and use of examples within this area.

\section{Examples}

Examples form an integral part of the discipline of mathematics and have played an important role in the teaching and learning of mathematics throughout history (Bills et al., 2006). Examples offer insight into the nature of mathematics through their use in demonstrating methods, in explanations, in proofs and in concept development; and are one of the main tools used to illustrate and communicate concepts between teachers and learners (Bills et al., 2006). In this paper, the author focuses on two types of examples used in mathematics teaching: worked examples, which are questions worked through by a teacher or textbook, and exercises, which are questions to be worked on by learners as a means of practicing a specific technique (Watson \& Mason, 2005).

Examples are considered important from the learning perspective because mathematics is learned by becoming familiar with examples that demonstrate or illustrate mathematical ideas and by constructing generalisations from examples (Watson \& Mason, 2005). Therefore, the mathematical examples presented to learners directly influence what they learn. Examples are also important from the teaching perspective. Leinhardt et al. (1990) as cited in Bills et al. (2006) argue that examples are communicative devices that are fundamental to the mathematical explanations offered by teachers, and further note that:

Explanations consist of the orchestrations of demonstrations, analogical representations and examples. [...]. A primary feature of explanations is the use of well-constructed examples, examples that make the point but limit the generalization, examples that are balanced by non- or counter-cases (2006:9).

The purposes underlying a teacher's use of examples in mathematics teaching varies (Rowland, 2008). A teacher may use an example of a procedure as a particular instance of a generality, that is, as an example of something (Mason \& Pimm, 1984; Rowland, 2008; Watson \& Mason, 2005). Here the teacher's example selection is aimed at learners abstracting the mathematical concept embodied in the particular example. Teachers may also use examples as an example for practicing something these are usually called 'exercises' (Rowland, 2008; Watson \& Mason, 2005). So, if a teacher has recently explained to her Grade 3 class how to do column subtraction with decomposition, she may then want to give her learners some examples as an exercise to help them remember the procedure and to gain fluency with it. Here too the teacher's choice of examples and variables is not arbitrary. These examples must ideally be graded from relatively easy to more challenging (so that learners experience success and gain confidence with the procedure). These exercise examples should also expose learners to the range of problem types that they may encounter (Rowland, 2008). 


\section{Teachers' example spaces}

Watson and Mason (2005) suggest that examples do not exist in isolation in one's mind but are interconnected and can be seen as members of a structured 'space', which they call a personal example space. One's personal example space is what is accessible in response to a particular problem, in a particular context, in relation to one's disposition at that time (Bills et al., 2006). The collection of examples which one has access to at any moment and the richness of interaction between those examples play a major role in the sense one can make of the task set or the activity engaged in (Bills et al., 2006). The work done by Watson and Mason with regard to personal example spaces primarily refers to learners, but in a South African context with evidence of poor example sequencing and the identification of disconnections in teaching (Venkat \& Adler, 2012), this notion has been extended to teachers. Watson and Mason (2005) note that teachers' example spaces are individual and situational. What teachers have access to within their example space depends on many things, including: their recent experiences; the wording of particular prompts; their inclination towards something; their assumptions about the topic; and the particular situation. Teachers' example spaces can be both beneficial and limiting with regard to teaching and learning mathematics. The examples a teacher offers her class regarding a particular topic will come from her own example space, which, in turn, will arise from her knowledge of not only mathematics, but also her knowledge of how children learn early number.

A teacher's example space concerning number and number operations figures within what she will make available to learn when teaching number topics (Watson \& Mason, 2005). For example, in the teaching of addition and subtraction, if a teacher only uses the 'join' and 'separate' problem types this may suggest that only these two conceptions make up that teacher's example space for addition and subtraction. However, Zazkis and Leikin (2007) caution that the adage 'absence of evidence is not evidence of absence' applies to our understanding of teachers' example spaces too. Therefore, if a teacher only uses the 'join' and 'separate' conceptions of addition and subtraction it does not mean that the 'part-part-whole' or 'compare' conceptions of these operations are not part of her example space. It simply means that 'join' and 'separate' are the conceptions of addition and subtraction that she has access to from her example space in that situation, at that time, within her teaching i.e. her accessible example space (Bills et al., 2006).

Rowland (2008) maintains that a teacher's choice of examples relates to the idea of awareness. He highlights particular aspects of teachers' awareness of variables, sequencing, representations, and learning objectives when selecting and using examples. These four categories of exemplification are not distinct - which means that a teacher's use of an example in a particular situation can show more than one type of awareness.

Teachers' selection of examples must take account of variables because examples of most mathematical objects consist of two or more parts, or variables, and by taking 
account of variables learners will be exposed to a range of possible problem types. What is important here is that the role of different variables must be clear, especially when teaching a new concept or procedure. Thus the examples selected by the teacher should ideally be the result of careful consideration. Here the teacher's choice of example and the variables used show her understanding of the nature of that concept and her awareness of possible variation, i.e. knowing which elements may vary within the context of that example and which have to remain the same (Rowland, 2008). Based on Marton and Booth's (1997) idea of 'dimensions of variation' an aspect only becomes available to learn through discerning variation, thus the role of variables in mathematical objects and how they are varied across the example space is important for learning.

Rowland (2008) maintains that teachers' examples must also take account of sequencing as examples are usually presented in a predetermined 'graded' sequence so that learners experience success with routine examples before trying more challenging ones. Although the sequence of most examples are controlled, examples can also be presented in a random sequence especially during interactive teaching (Rowland, 2008). The sequencing of examples and the aspects which are varied in that sequence are important in affording learners access to key features of a concept or technique (Watson \& Mason, 2006; Bills et al., 2006). Within this, it is important for the example space to range across different conceptions of key ideas - e.g. examples of subtraction presented should provoke the need for viewing subtraction as 'take away' (e.g. $11-2$ ) and as 'difference' (e.g. $11-8$ ). What is evident from literature thus far is that the range of examples selected by the teacher and the variables used are indicators of a coherent grasp of the mathematical concept concerned.

According to Van Patten, Chao, and Reigeluth (1986) there are two steps involved when a teacher wants to take account of sequencing: firstly, she must identify what elements are to be sequenced, and secondly, what organising principle will be used to sequence these. These authors delineate Merrill's (1983) five specific prescriptions for micro-sequencing which are:

1. Presenting the 'worked example' or general rule before the learners' exercise for near transfer of the concept learned;

2. Presenting the learner exercise before the rule or generality for far transfer of the concept learned;

3. Arranging examples in a divergent sequence (i.e. make successive examples different from each other in some way);

4. Arranging examples in an easy-to-difficult sequence; and

5. Providing similar non-examples matched to examples.

Rowland (2008) also highlights the manner in which teachers' examples are represented because this can provide learners with more or less generality in relation to access to the concept being taught. Further, teachers need to consider the nature 
of the mathematical content to be taught and the characteristics of the learners who will learn that content when planning a lesson and deciding on appropriate examples and representations to use (Nistal, Van Dooren, Clarebout, Elen \& Verschaffel, 2009). Particular representations often foreground particular aspects of the given mathematical concept while obscuring other equally important aspects (Ball, 1993) while some representations might be more adequate as expressions of knowledge and as thinking tools than others for particular mathematical concepts (Cobb, Yackel \& Wood, 1992). Taken together this research points to the teacher needing an understanding of the advantages and limitations a particular representation can have on the process of teaching and learning.

Finally, Rowland (2008) argues that teachers' examples should be tailored to the learning objective because this is the ultimate purpose for which they are used. This category was not used for this paper as the author did not have access to teacher's lesson plans and thus could not determine what teachers' learning objectives for their lessons were.

\section{Research design}

Two foundation phase teachers, Zelda and Deborah ${ }^{1}$ who teach Grades 1 and 2 respectively, from one of the schools participating in the WMC-P pilot course make up the sample of this study. These two teachers were selected based on their differing CK course pre-test scores (Zelda was stronger and Deborah weaker) and their willingness to participate in the study. By comparing their selection and use of examples when teaching numbers, the author was able to see each individual teacher more deeply through analysing relative presences in data drawn from the other teacher.

The data set worked with consisted of lesson observations (field notes and video recordings) of two non-consecutive lessons (focused on number work) presented towards the end of the 2012 academic year by each participant. Video data were later fully transcribed to capture all teacher talk and teacher-learner interaction, writing on the board and presentation of examples. Lesson overviews were constructed wherein episodes were demarcated by tasks, and the examples, activity and representations used within them. Teaching format changes demarcated episodes while tasks were determined by what was presented by the teacher as the focus of attention. Following Mason and Johnston-Wilder's (2006) distinction between task and activity, the activity outlined described what happened in the enactment of the task. Data from the lesson overviews were then analysed using the analytical framework formulated from three of Rowland's (2008) categories of exemplification, viz. taking account of variables, sequencing, and representations with additional literature-based indicators used under relevant categories.

Deborah's first lesson - focused on addition - contained nine episodes ranging across counting, followed by ordering numbers on a number line, worked examples of addition on a number line and examples for practising addition on a number line. Her second lesson - focused on division as sharing - contained four episodes ranging 
across worked examples of sharing followed by examples for practising sharing in pairs and individual work.

Zelda's first lesson - also focused on addition - contained five episodes ranging across counting, matching numbers (1-15) to number names, ordering numbers on a number line, worked examples of adding on a number line and exercise examples for practising addition on a number line. Her second lesson - focused on sharing contained six episodes ranging across estimation followed by worked examples of sharing and exercise examples for practising sharing in pairs.

Given the small classroom observation dataset, the exploratory nature of this analysis and the localised nature of ensuing claims must be emphasised.

\section{Research findings}

\section{Taking account of variables}

When looking for evidence of taking account of variables within and across lessons presented by Deborah and Zelda, the author followed Watson \& Mason's (2006) attention to what changed and what stayed the same across example sequences.

\section{Deborah}

In Deborah's first lesson the most noteworthy aspect that remained fixed across all episodes was the 'join' conception of addition presented in both worked and exercise examples. This conception was reinforced with explanations like '[addition] means we put things together'. Whilst evidence from one lesson does not necessarily constitute a limited example range in relation to addition problem types (Carpenter et al. (1999), Deborah may have restricted learners' understanding of the operation and the range of addition problems learners would be able to solve independently later on. Carpenter et al. (1999) further suggest that 'join' problems can be varied by changing the variable that is unknown. Deborah did not take account of this dimension of possible variation and presented all the 'join' problems with the 'result unknown', e.g. $3+5=\square$. So, even though Deborah chose to 'fix' the type of addition problem to the 'join' conception, she could still have taken account of variables by presenting these using the 'change unknown' as $3+\square=8$ or the 'start unknown' as $\square+5=8$. Here the dimensions of possible variation and permissible change which Rowland (2008) maintains must be reflected within teachers' examples were not reflected in Deborah's selection of examples. Thus Deborah's examples used here did not expose learners to the range of possible types of addition problem that they may encounter (Carpenter et al., 1999).

In Deborah's second lesson she took account of variables in episodes 3, 4 and 5 by increasing the divisor and dividend in her worked examples and learner exercise. Deborah also varied the type of examples presented in the learner exercise of the second lesson - word problems and context-free problems. 


\section{Zelda}

In episode 1 of Zelda's first lesson the aspects of the examples that varied were: the interval or size of the count ( 3 and 2); the direction of the count (forward and backward); and the start and end points of the counting sequences (counting in 35 from 3 , counting in 25 from 6 , and counting backward in 25 from 29 ). By using variation in this way Zelda also varied the level of difficulty in this mental starter activity because counting from the first number in a counting sequence is easier than starting at a number that is further along in the counting sequence, for example, starting at 6 when counting in $2 \mathrm{~s}$. Anghileri (2006:33) maintains that the latter is more demanding because she likens it to 'trying to complete the lines of a song or poem but starting in the middle'.

Zelda also took account of variables in episode 5 of her second lesson. In the preceding episode the objects to be shared were 'chocolates' and the action needed to share the chocolates equally was to 'cut' the chocolates. In this successive example three learners shared fourteen fun fair tickets equally and got four fun fair tickets each with two tickets left over. When asked what should be done with the tickets that were left over some learners offered: 'Cut the tickets'. Other learners objected to this suggestion and by way of a quick class discussion led by the teacher, all the learners agreed that the left over tickets could not be cut because this would render them useless. Here variation in the objects to be shared incorporated a counterexample that highlighted the role of the context in determining the handling of the remainder element.

\section{Taking account of sequencing}

For the purposes of this paper, teachers' worked examples and learner exercises were the main elements considered for sequencing.

\section{Deborah}

In Deborah's first lesson, she told learners that number lines could be used to add and then she demonstrated how to do so using two worked examples $(2+6$ and $10+10)$. Thereafter learners were required to use the procedure just explained by the teacher to show addition of exercise examples $(3+5$ and $10+6)$ on number lines drawn in their workbooks. Here Merrill's first prescription regarding micro sequencing, i.e. generality, in relation to the number line model, before example for near transfer (Van Patten et al., 1986), was evident as an organising principle. The sequencing of these worked examples $(2+6$ and $10+10)$ and exercise examples $(3+5$ and $10+6)$ seems to also show a 'divergent sequence' which relates to Merrill's third prescription regarding micro sequencing (Van Patten et al., 1986). The difference between these successive examples was that the initial problem consisted of single-digit numbers while the second problem had at least one two-digit number. Here the sequence of examples could also show an attempt at graded sequencing because two-digit numbers are bigger in size than single-digit numbers and bigger numbers are generally more challenging to work with (Anghileri, 2006). However, if the sequencing here 
was indeed intended to be graded it was only so on a superficial level because the succeeding examples can be viewed as less challenging than the initial examples given that children often learn 'double' number facts like $10+10$ relatively quickly and also find adding a single digit number to 10 (e.g. $10+6$ ) relatively easy (Anghileri, 2006).

\section{Zelda}

During her first lesson Zelda used a random sequence of numbers to teach the ordering of numbers from nought to fifteen (Rowland, 2008). The activity involved 'fishing' a fish-shaped card out of the pond and placing these numbered fish in order on a number line drawn on the board. By asking learners to 'fish' numbers out of the 'pond', the following random sequence of numbers was generated: $8,7,3,11,0,13,15$, $1,5,6,4,12,9,14,10$ and 2 . This random sequence worked well for this task because learners had to display number identification as the symbolic numbers they 'fished' were not produced in any order. Learners who were struggling with identifying symbolic numbers were thus easily noticed and immediately helped.

This random sequencing of numbers also helped the teacher to draw attention to the possibility of shift from 'count all' to the more efficient 'count on' strategy as is evident in this extract from the lesson transcript:

Lr1: l've got seven.

Tr: Where will number seven go on the number line?

(Lr1 points to the hash mark before fish number 8 previously placed on the number line.)

Tr: $\quad$ Very good.

(Lr1 places fish no. 7 correctly on the no. line without any overt counting.)

Lr2: I have fish number three.

(Starting at the first hash mark, Lr2 counts incorrectly in ones from 0 and is helped by the teacher and class to recount. Lr2 correctly places fish

number 3.)

Lr3: I have number eleven.

(Lr3 starts counting from the first hash mark in ones from o on the number line and then the teacher intervenes...)

Tr: Wait. Why are you counting from nought? Is eleven bigger than eight? (Pointing to 8 on no. line.)

Lr3: Yes.

Tr: $\quad$ So, you can count on from eight to find the place for number 11.

Lr3: Eight, nine, ten, eleven.

(Lr3 counts on from fish no. 8, pointing to each hash mark with his finger, and places fish no. 11 correctly on the number line)

In episode 2 of the second lesson Zelda controlled the sequence of symbolic numbers given to learners which they had to match to the number names written in sequence 
on the board. By looking at the sequence of the symbolic numbers chosen by Zelda (i.e. 15, 6, 4, 11, 10, 1, 9, 8 12, 5, 2, 3, 13, 7 and 14) it seems as if Merrill's third prescription regarding micro sequencing, i.e. arranging examples in a divergent sequence, was used an as organising principle because she alternated between bigger and smaller numbers which probably made the task of identifying symbolic numbers and matching them to their number names more challenging for her Grade 1 learners.

\section{Taking account of representations}

A teacher's selection and use of specific representations when teaching mathematics is driven (in part) by the need to make an abstract concept more accessible to learners (Rowland, 2008).

\section{Deborah}

In Deborah's first observed lesson, her use of the number line to add in both worked examples went awry. In the first example Deborah used a number line calibrated in two's, from nought to twelve, to add $2+6$ and got an incorrect answer because she ignored the calibration and enacted unit counting. Then, after realising her mistake, she changed the hash marks on the number line from multiples of two to ones, but did not do so for the whole number line, resulting in a calibrated number line with an irregular scale. Research shows that number lines which model the counting sequence can provide learners with the mental imagery needed for calculation strategies (Beishuizen, 1999, as cited in Anghileri, 2006). Here Deborah's choice of a number line representation for learners to use as a thinking tool (Cobb et al., 1992) for addition was thus a good choice. However, how Deborah used the representation in these worked examples did not provide learners with greater access to the mathematical concept or procedure being taught (Rowland, 2008) for many reasons. Firstly, the number range of the examples was so limited that learners did not need to use the number line to add - they simply used a recalled fact; the choice of a well-known double $(10+10)$ also negated the need for adding on a number line as doubles are some of the easiest number facts for children to remember (Anghileri, 2006); and finally, the way in which Deborah demonstrated how to add on the number line resulted in inconsistent calibrations in her number line representation, making it procedurally confusing. Learners' disagreement with the teacher's actions indicated at least some awareness of these inconsistencies.

Across Deborah's second lesson the representations that she used to demonstrate worked examples on sharing were used flexibly and were also suited to the action of sharing. Here Deborah showed awareness of representational progression by using concrete (i.e. play dough), iconic (drawings) and symbolic-syntactic representations in the lesson (Ensor et al., 2009).

\section{Zelda}

Zelda used a few well thought out representations - which literature suggests enhances learners' understanding of number (Askew \& Brown, 2003) - in a planned 
(and sometimes spontaneous) manner that were suited to the tasks, for example, using a number line for adding and a 'count on' strategy.

During episode 1 from the first lesson, learners counted forward and backward in intervals of 3 and 2 as directed by the teacher. No representation was used for most of this task but towards the end of the last counting routine (counting backwards in 2s from 29) learners got stuck and Zelda referred them to the 100 wall chart which was hanging on a window towards the back of the class. The use of this wall chart seemed like a spontaneous decision (because all other representations that were used in the lesson were either stuck on the board in the front of the class or kept close-by on Zelda's table). Here the spontaneous use of a representation afforded the learners greater access to skip counting backwards from an odd number which they struggled to do mentally.

Literature within the educational landscape points to the importance of connections being established between different representational forms and between different mathematical ideas and facets of the mathematics curriculum in the teaching and learning of early number (Askew et al., 1997; Haylock \& Cockburn, 2008). In Zelda's first lesson ample empirical evidence showed how she took account of representational connections. For example, during episodes 2, 3, 4 and 5 of this lesson, connections were established between the words, symbols, pictures, and actions that Zelda used to explain adding on a number line. The number line that was constructed by the learners 'fishing' numbers in episode 3 was also used in episode 4 (when Zelda demonstrated how to add on the number line) and replicas thereof were used by learners in episode 5 for individual work. Across these four episodes the same number range, and thus also the same number symbols and spoken and written words were used in successive inter-linking tasks.

\section{Teachers' example spaces}

The author's interest in teachers' selection and use of examples when teaching number-related tasks was ultimately driven by an interest in how this relates to their example spaces. As mentioned previously, a teacher's example space concerning a particular subject or topic determines what they will make available to learners when they teach that subject or topic (Watson \& Mason, 2005). Therefore, a teacher's example space related to number skills and number operations has bearing on what opportunities to learn number she creates for the learners in her class. Data from this study provides empirical evidence of how these two teachers provided their learners with opportunities to learn number in different ways.

With regard to taking account of variables - both teachers' examples (worked examples and exercises) only used the 'join - result unknown' conception of addition which limited the range of problems learners were exposed to. When Deborah did use variation during her first lesson by varying the calibrations on the number line it was not done successfully. In contrast, when Zelda took account of variables in both lessons she did not vary too many aspects thereby encouraging learners to see tasks 
as 'conceptually related' instead of separate, individual tasks (Zawijewski and Silver, 1998, as cited in Watson \& Mason, 2006). What is also interesting to note is that both teachers selected the same sharing examples for the learners' exercise in their second lessons even though Zelda teaches Grade 1 and Deborah Grade 2. This raises a question with regard to the number range of the variables in the examples Deborah selected for her class.

Both teachers took account of sequencing in their selection and use of examples - using Merrill's second (generality before example), third (divergent sequence) and fourth (easy-to-difficult sequence) specific prescriptions regarding micro sequencing (Van Patten et al., 1986). Both teachers presented a general model for a worked example to the class before expecting learners to attempt examples using the same model in their learner exercise either as pair-work or as individual tasks. Both teachers also used different successive examples, for example, Deborah varied the number of digits in examples during her first lesson and in Zelda's second lesson she used tickets as the objects that should be shared which could not be 'cut' like the chocolates shared previously. Both teachers used controlled sequencing of examples so that examples were more or less graded in an easy-to-difficult sequence, but only Zelda used random sequencing in her lessons.

With regard to taking account of representations - both teachers introduced the number line as a 'thinking tool' for adding (Cobb et al., 1992) and this was a judicious choice of representation because literature points to number lines providing learners with good mental imagery for calculation strategies (Anghileri, 2006). However, Deborah struggled to connect her non-unit calibrated number line to her worked examples on addition, while Zelda's explanation and demonstration regarding the use of a number line was coherently connected. The incidence of disrupted connections in Deborah's use of representations is higher than in Zelda's. Deborah's choice of examples negated the usefulness of her representations because most learners appeared able to solve the problems mentally. During Deborah's second lesson, representations were used in progressively more abstract ways, i.e. from the concrete sharing of play dough, to iconic pictures of sharing drawn on the board, and eventually symbolic-syntactic number sentences (Ensor et al., 2009). Similar representational progression was evident in Zelda's lessons, for example, in her first lesson learners acted on concrete objects to construct a number line then they used a number line to add (symbolic number-based), and finally learners used number sentences to show each calculation (symbolic-syntactic). What stood out about Zelda's use of representations across lessons was the coherently connected way in which she used them.

\section{Conclusion}

Data gathered and analysed in this paper show similarities and differences in the participants' selection, use and representation of examples. The notable difference across teachers' lessons was that the number of examples presented by Zelda as 
examples of something, as well as the number of examples for practicing the concept or procedure learnt, was higher than Deborah's. Further, the number range in the examples presented by Deborah was generally lower than that of the examples presented by Zelda. These differences in the number range used and in the multiplicity of the two teachers' examples are significant because Zelda taught a Grade 1 class while Deborah taught Grade 2. Zelda, the teacher with the higher CK score, made coherent connections more consistently between different representational forms and between different ideas in mathematics. The body of work done by Askew et al. (1997) suggests that such 'connectionist' teachers have classes with greater learner gains than teachers who are not considered 'connectionist'. Findings from this study point to possible associations between a higher CK score and the extent of a teacher's example space and more coherent connections - which could prove interesting to explore further using a bigger sample. However, the findings are less clear on differences in terms of representational flexibility and progression. Analysis of Deborah's teaching shows that the gains of flexibility and progression can be disrupted by circularity and disconnections between examples and representations used to solve some problems. With regard to opening opportunities for learners to develop number sense - there is evidence pointing to more connected and extended handling of ideas in Zelda's lessons. The data analysed in this paper and the preponderance of literature regarding the importance of establishing coherent connections when teaching and learning mathematics suggests that improving representational connections may be more immediately important in order to support the work of primary mathematics teaching in the South African landscape.

\section{Endnotes}

1. Both pseudonyms.

\section{References}

Anghileri, J. 2006. Teaching number sense. London: Continuum.

Askew, M. \& Brown, M. 2003. How do we teach children to be numerate? A BERA Professional User Review (pp. 1-17). Kings College London: BERA.

Askew, M., Brown, M., Rhodes, V., Wiliam, D. \& Johnson, D. 1997. Effective teachers of numeracy: A report of a study carried out for the Teacher Training Agency. London: Kings College, University of London.

Ball, D.L. 1993. Halves, pieces and twoths: Constructing and using representational contexts in teaching fractions. In T.P. Carpenter, E. Fennema \& T.A. Romberg (Eds.), Rational numbers: An investigation of research (pp. 328-375). Hillsdale, NJ: Erlbaum.

Ball, D.L. \& Bass, H. 2003. Toward a practice-based theory of mathematical knowledge for teaching. Paper presented at the Annual meeting of the Canadian mathematics education study group. 
Bills, L., Dreyfus, T., Mason, J., Tsamir, P., Watson, A. \& Zaslavsky, O. 2006. Exemplification in mathematics education. Paper presented at the $30^{\text {th }}$ Conference of the International Group for the Psychology of Mathematics Education, Prague, Czech Republic.

Carnoy, M. \& Chisholm, L., et al. 2008. Towards understanding student academic performance in South Africa: A pilot study of Grade 6 mathematics lessons in South Africa. Pretoria: HSRC.

Carpenter, T.P., Fennema, E., Franke, M.L., Levi, L. \& Empson, S.B. 1999. Children's Mathematics: Cognitively Guided Instruction. Portsmouth, NH: Heinemann.

Cobb, P., Yackel, E. \& Wood, T. 1992. A constructivist alternative to a representational view of mind in mathematics education. Journal for Research in Mathematics Education 23(1):2-33.

Department of Basic Education (DBE). 2011a. Report on the Annual National Assessments of 2011. Pretoria: DBE.

Department of Basic Education (DBE). 2011b. Curriculum and Assessment Policy Statement (CAPS): Foundation Phase Mathematics, Grade R - 3. Pretoria: DBE.

Ensor, P., Hoadley, U., Jacklin, H., Kuhne, C., Schmitt, E., Lombard, A. \& Van den HuewelPanhuizen, M. 2009. Specialising pedagogic text and time in Foundation Phase numeracy classrooms. Journal of Education 47:5-29.

Haylock, D. \& Cockburn, A. 2008. Understanding mathematics for young children. London: Sage.

Heize, A., Star, J. R., \& Verschaffel, L. 2009. Flexible and adaptive use of strategies and representations in mathematics education. ZDM Mathematics Education, 41:535-540.

Mason, J. \& Johnston-Wilder, S. 2006. Designing and using mathematical tasks. St Albans, England: Tarquin Publications.

Mason, J. \& Pimm, D. 1984. Generic examples: Seeing the general in the particular. Educational Studies in Mathematics 15(3):277-290.

McIntosh, A., Reys, B.J. \& Reys, R.E. 1992. A proposed framework for examining number sense. For the Learning of Mathematics 12(3):2-8.

Moloi, M.Q. \& Chetty, M. 2010. The SACMEQ III Project in South Africa: A study of the conditions of schooling and the quality of education. Pretoria: Ministry of Basic Education.

Morrison, S.S. 2013. Exploring two Foundation Phase teachers' selection and use of examples and representations in number-related tasks. Unpublished Master's Research Report, University of the Witwatersrand. Johannesburg.

Mullis, I.V.S., Martin, M.O. \& Fay, P. 2008. TIMSS 2007 International Mathematics Report: Findings from IEA's Trends in International Mathematics and Science Study at the Fourth and Eighth Grades. Chestnut Hill, MA: TIMSS \& PIRLS International Study Centre, Boston College. 
The National Commission on Teaching and America's Future (NCTAF). 1996. What matters most: Teaching for America's future. New York: NCTAF.

Nistal, A.A., Van Dooren, W., Clarebout, G., Elen, J. \& Verschaffel, L. 2009. Conceptualising, investigating, and stimulating representational flexibility in mathematical problem solving and learning: A critical review. ZDM Mathematics Education 41:627-636.

Reeves, C. \& Muller, J. 2005. Picking up the pace: Variation in the structure and organisation of learning school mathematics. Journal of Education 37:103-130.

Reys, R., Reys, B., McIntosh, A., Emanuelsson, G., Johansson, B. \& Yang, D. 1999. Assessing number sense of students in Australia, Sweden, Taiwan, and the United States. School Science and Mathematics 99(2):61-70.

Rowland, T. 2008. The purpose, design and use of examples in the teaching of elementary mathematics. Educational studies in mathematics 69:149-163.

Schollar, E. 2008. Final Report: The primary mathematics research project 2004-2007Towards evidence-based educational development in South Africa. Johannesburg.

Shumway, J. 2011. Number sense routines: Building numerical literacy every day in $\mathrm{K}-3$. USA: Stenhouse Publishers.

Van Patten, J., Chao, C. \& Reigeluth, C.M. 1986. A review of strategies for sequencing and synthesizing instruction. Review of Educational Research 56(4):437-471.

Venkat, H. 2013. Reading between the lines: Examining 'opportunity to learn' in a sample of Eastern Cape workbooks. In S. Motala, V. Dieltiens \& Y. Sayed (Eds.), Finding place and keeping pace - Exploring meaningful and equitable learning in South African schools. South Africa: HSRC Press.

Venkat, H. \& Adler, J. 2012. Coherence and connections in teachers' mathematical discourses in instruction. Pythagoras 33(3):1-8.

Venkat, H. \& Naidoo, D. 2012. Analyzing coherence for conceptual learning in a Grade 2 numeracy lesson. Education as Change 16(1):21-23.

Watson, A. \& Mason, J. 2005. Mathematics as a constructive activity: Learners generating examples. Mahwah, NJ, USA: Erlbaum.

Watson, A. \& Mason, J. 2006. Variation and mathematical structure. Mathematics Teaching (incorporating Micromath) 194:3-5.

Zazkis, R. \& Leikin, R. 2007. Generating examples: From pedagogical tool to research tool. For the Learning of Mathematics 27(2):15-21. 